\title{
NOTES
}

\section{Photostability and photostabilizing effect of humic acids}

\author{
M. Mekkaoui, ${ }^{1}$ M. Elazzouzi, ${ }^{1}$ A. Bouhaouss, ${ }^{1}$ M. Ferhat, ${ }^{1}$ \\ J. M. Chovelon, ${ }^{2}$ and P. Meallier ${ }^{2}$ \\ ${ }^{1}$ Département de Chimie, Faculté des Sciences de Rabat, Av Ibn batouta, BP 1014 Rabat/Maroc \\ ${ }^{2}$ Laboratoire d'Application de la Chimie à l'Environnement (LACE)-UMR 5634-Photochimie, Université \\ Claude Bernard-Lyon 1, 43 Boulevard du 11 Novembre 1918, Villeurbanne-Cedex/France
}

\begin{abstract}
The photolysis of Humic Acids (HA) extracted from Moroccan soil in water under simulated sunlight method has been studied. The photochemical degradation of HA in concentration (30 mg/L) has been followed by TOC (Total Organic Carbon) and E4/E6 ratio (The E4/E6 value widely used to characterize humic acids is the ratio of absorption intensities at 465 and $665 \mathrm{~nm}$ ). HA were found photostable after $24 \mathrm{~h}$ of irradiation exposure and produce a screen effect on photochemical degradation of TRB (Tribenuron-methyl) and IMAZ (Imazapyr) herbicides.
\end{abstract}

\section{INTRODUCTION}

Humic substances representing the main fraction of organic matter [1] receive increased attention because their reactivity as sunlight absorbers. Depending on their origin, humic substances have a remarkable ability to absorb light and transfer this energy to other substrates and in some cases strongly affect photolysis of xenobiotics. In water and in soils humic substances have been found to act as photosensitisers when irradiated at wavelength longer than $290 \mathrm{~nm}$ [2] and they have also been reported to produce oxygen species upon irradiation [3], and be able to photoinduce the transformation of pesticides $[4,5]$. They could behave as quenchers or as light scatters [6].

In order to obtain new information on the herbicides behaviour in the presence of HA we studied in this work photochemical behavior of HA alone and photodegradation of herbicides (TRB and IMAZ) in the presence of $\mathrm{HA}$, at different HA/herbicide ratios.

The herbicides Tribenuron-methyl (TRB); methyl2-(4-methoxy-6-methyl-1,3,5-triazin-2-yl (methyl) carbamoyl sufamoyl) benzoate and Imazapyr (IMAZ); 2(4-isopropyl-4-methyl-5-oxo-2-imidazolin-2-yl) nicotinic acid are two herbicides widely used to control a wide range of weeds $[7,8]$. They have been tested for weed control in cereal crops and sugar beet in the area from which humic acids were extracted $[8,9]$ and little is known about their modes of degradation $[8,9]$.

The photodegradation experiments were carried out using a xenon lamp. HA were isolated from agricultural soil from Morocco and are known by their reactivity with heavy metal ions and pesticides $[10,11]$.

\section{MATERIALS AND METHODS}

Humic acids. The HA used in this investigation are from surface horizon $(0-20 \mathrm{~cm})$ of soil originated from chaouia, which is agricultural and semiarid area in Morocco. Main physicochemical properties of the soil from which HA were extracted are $\left(\mathrm{C}_{\text {total }}=1.56\right.$; $\mathrm{N}_{\text {total }}=0.16$; $\left.\mathrm{pH}\left(\mathrm{H}_{2} \mathrm{O}\right)=7.7\right)$

HA were extracted by $0.1 \mathrm{M} \mathrm{NaOH}$ and $0.1 \mathrm{M} \mathrm{Na}_{4} \mathrm{P}_{2} \mathrm{O}_{7}$ (v/v) mixture under nitrogen [12]. The sample was suspended in $2 \mathrm{~N} \mathrm{HCl}$ to remove carbonates and the above mixture was added with stirring for $16 \mathrm{~h}$. The solution was centrifuged to eliminate suspended clay and acidified at $\mathrm{pH}$ lower than 2 with $6 \mathrm{~N} \mathrm{HCl}$. The HA precipitate was separated by centrifugation and purified by $\mathrm{HCl} / \mathrm{HF}$ $0.5 \%(\mathrm{v} / \mathrm{v})$ treatment. Dissolution into alkaline solution and precipitation by acid was repeated three times. The final alkaline solution was passed through an Amberlite IRN 77 cation exchange resin column to obtain an acid form of HA, which dialysed against distilled water and freeze dried. Characterization of HA was achieved by elemental analysis and determination of acidities [13] (Table 1).

Analytical procedure. UV-Vis absorption spectra were recorded using Uvikon 930 spectrophotometer. TOC contents were determined with a calibrated Carmograph 8 apparatus [11].

Photoreactor. Photodegradation processes were carried out using a cylindrical photoreactor placed in suntest Heraeus apparatus. The irradiation source was xenon lamp $\left(\mathrm{T}=20^{\circ} \mathrm{C}\right)$, which provides a good simulation of solar light. The lamp was placed above the surface of the solution. The solution was homogenized by continuous stirring with a magnetic stirrer. 
Procedure. $50 \mathrm{ml}$ of HA at concentration (30 mg/l), were exposed for photodegradation at various illumination time. Experiments were carried out at $\mathrm{pH}=7.0(\mathrm{pH}$ of environmental interest), buffered with a mixture of $\mathrm{K}_{2} \mathrm{HPO}_{4} 3.9 \times 10^{-4} \mathrm{~mol} / \mathrm{l}$ and $\mathrm{KH}_{2} \mathrm{PO}_{4} 6.1 \times 10^{-4} \mathrm{~mol} / \mathrm{l}$ $(1 / 1 ; \mathrm{v} / \mathrm{v})$.

\section{RESULTS AND DISCUSSION}

Humic acids properties. The characteristics of HA (Table 1) obtained are close to those reported in the literature data [14] with some differences in the determined chemical properties such as total acidity and acid group.

Table 1. Analytical characteristics of HA extracted.

\begin{tabular}{lr}
\hline C\% & 41.70 \\
H\% & 2.51 \\
N\% & 2.47 \\
O\% (by difference) & 53.32 \\
Total acidity (meq/g) & 6.04 \\
Phenolic acidity (meq/g) & 0.77 \\
Carboxylic acidity (meq/g) & 3.93 \\
Mineral acidity (meq/g) & 1.34 \\
\hline
\end{tabular}

Photolysis of HA. Generally HA have no spectral characteristics in UV. Due to the complex nature of HA, the UV spectrum of HA shows a continuous absorption without typical peaks, and the absorbance increases with the decreasing wavelength. However, The E4/E6 value, which is the ratio of absorption intensities at 465 and $665 \mathrm{~nm}$, is widely used to characterize humic acids. The E4/E6 ratio is supposed to decrease with increasing condensation of aromatic humic constituent's [15]. And the E4/E6 ratio is governed by the molecular size [16].

According to the experimental data, the values of TOC and E4/E6 ratio against irradiation time were given in Table 2.

Table 2. E4/E6 and TOC at different irradiation times.

\begin{tabular}{lcc}
\hline t (irr) (h) & E4/E6 & TOC \\
\hline 0 & 2.00 & 0.52 \\
2 & 1.90 & 0.52 \\
5 & 1.91 & 0.50 \\
8 & 1.91 & 0.51 \\
14 & 1.90 & 0.52 \\
24 & 1.90 & 0.50 \\
\hline
\end{tabular}

The results show that the E4/E6 ratio as well as the TOC value are both constant with increasing time of irradiation, reflecting photostability of HA molecules after $24 \mathrm{~h}$ of continuous irradiation.

Simultaneous photolysis of HA and Herbicide (TRB and IMAZ) molecules. The effect of the presence of HA on photolysis of TRB and IMAZ in water was studied by irradiation of different mixtures of HA/herbicide (0.5:1 and 1:1 by volume). The results are reported in Table 3 .
According to the results given in Table 3, the addition of the HA to the solution of TRB or IMAZ herbicides results in a decrease in kinetic rate constant $(\mathrm{k})$ and a remarkable increase in the half-life $\left(t_{1 / 2}\right)$. The result obtained clearly demonstrates that HA substances exhibit a screening effect on the photochemical degradation of the two herbicides.

The protective effect of HA on the TRB and IMAZ degradation could be explained with an inclusion and/or adsorption of the herbicide molecules in the humic matrix.

Table 3. Kinetic parameters of photolysis of TRB and IMAZ in the presence of HA.

\begin{tabular}{lcccr}
\hline & \multicolumn{2}{c}{ TBR } & \multicolumn{2}{c}{ IMAZ } \\
\cline { 2 - 5 } HA/herb & $\mathbf{k}\left(\mathbf{h}^{-\mathbf{1}}\right)$ & $\mathbf{t}_{\mathbf{1} / \mathbf{2}}(\mathbf{h})$ & $\mathbf{k}\left(\mathbf{h}^{-\mathbf{1}}\right)$ & $\mathbf{t}_{\mathbf{1 / 2}}(\mathbf{h})$ \\
\hline $0 / 1$ & 0.0029 & 267.8 & 0.242 & 2.9 \\
$0.5 / 1$ & 0.0013 & 524.6 & 0.015 & 44 \\
$1 / 1$ & 0.0012 & 552.2 & 0.014 & 49 \\
\hline
\end{tabular}

\section{CONCLUSION}

The photochemical behaviour of HA isolated from agricultural soil which have complicated molecular structure has been found photostable in buffered solution upon $24 \mathrm{~h}$ of irradiation. They induced a decrease of photolysis rate with respect to pure water solution of TRB and IMAZ molecules. This protective effect favours herbicide activity of TRB and IMAZ.

\section{ACKNOWLEDGEMENTS}

This work was supported as a part of linked research project between Morocco (CNCPRST) and France (CNRS).

\section{REFERENCES}

[1] R. L. Wershaw and G. R. Aiken, Humic substances in soils, sediments and water, Wiley Interscience, New York, 1995.

[2] L. Faust and J. Hoigne, Environ. Sci. Technol. 10 (1987), 958.

[3] J. P. Auger and C. Richard, J. Photochem. Photobiol. 84 (1994), 69.

[4] R. G. Zepp, P. F. Shlotezhauer, and R. M. Sink, Environ. Sci. Techno. 19 (1985), 16.

[5] J. P. Auger and C. Richard, Pestic. Sci. 46 (1996), 151.

[6] L. Scrano, S. A. Bufo, M. Mansour, and P. Meallier, Proceedings of Med. Conf. on Chemistry and Mediterranean Sea, 23-27 May, Tarento, Italy (1995), 212.

[7] A. K. Bhattacherjee and P. Dureje, Pestic. Sci. 55 (1999), 183.

[8] M. El azzouzi, A. Dahchour, A. Bouhaouss, and M. Ferhat, Weed Res. 38 (1998), 217.

[9] A. Satrallah, A. Dahchour, and E. M. Essassi, Fresenius. Environ. Bull. 7 (1998), 657. 
[10] H. Mountacer, M. El azzouzi, M. Ferhat, M. Mansour, and I. Scheunert, Fresenius. Environ. Bull. 6 (1997), 365.

[11] M. El azzouzi, These de $3^{\circ}$ Cycle, Université Mohammed V de Rabat-Maroc, 1988.

[12] R. Ertel and J. I. Hedges, Geochim. Cosmochim. Acta. 48 (1984), 2056.

[13] F. J. Stevenson, Humus chemistry: genesis, composition and reactions, 2nd edition, Wiley Interscience,
New York, 1994.

[14] C. Steelink and G. R. Aiken, Humic substances in solid sediments and water, Wiley Interscience, New York, 1985.

[15] M. M. Kononova, Soil organic matter, Pergamon Press Elmsford, New York, 1966.

[16] Y. Chen, N. Senesi, and M. Schnitzer, Soil Sci. Soc. Am. 41 (1977), 352. 


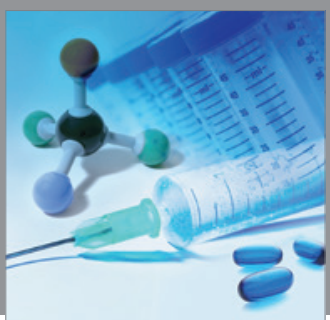

International Journal of

Medicinal Chemistry

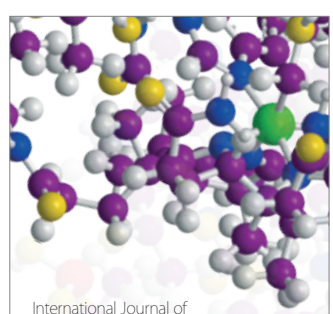

Carbohydrate Chemistry

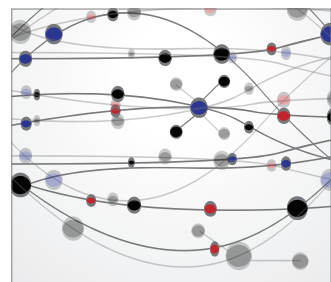

The Scientific World Journal
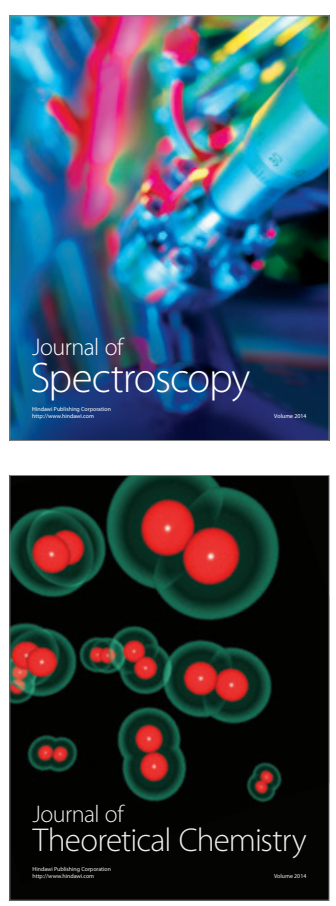
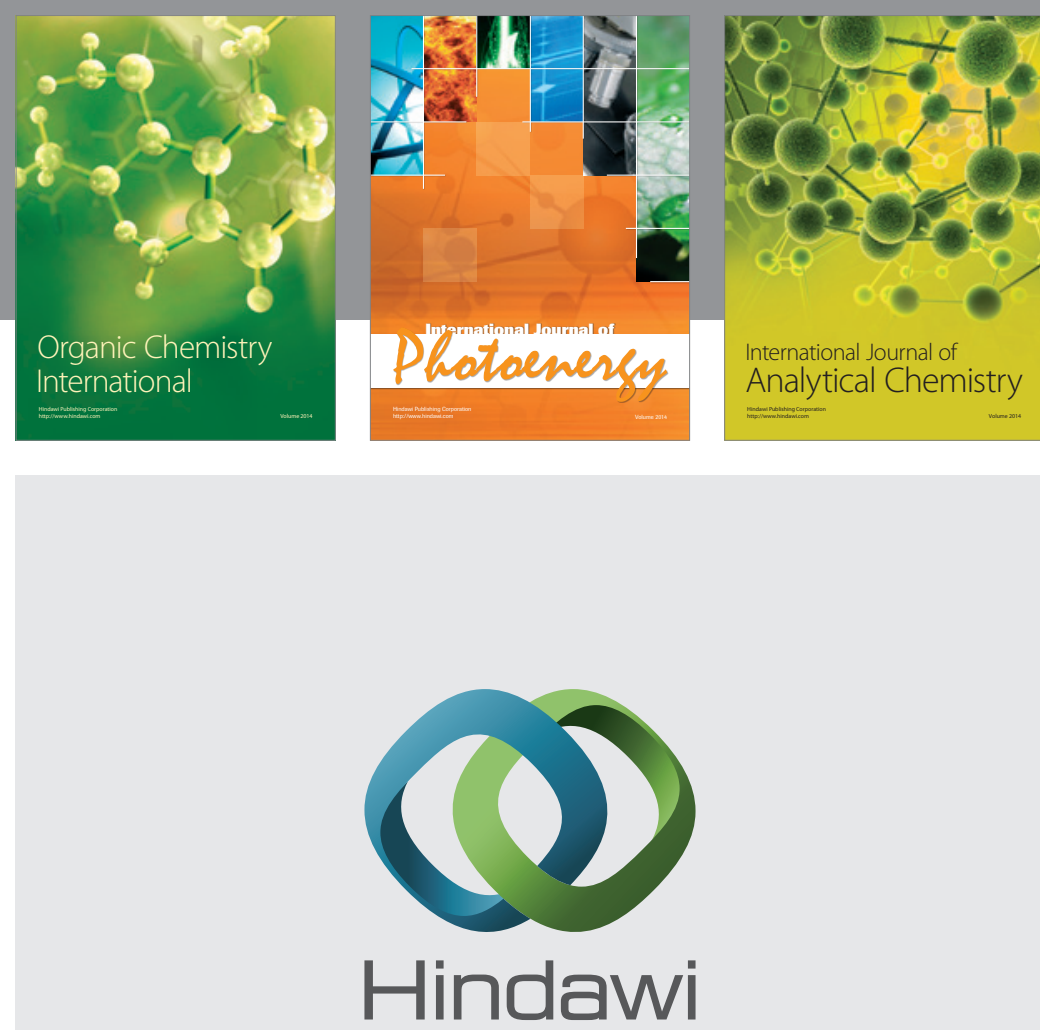

Submit your manuscripts at

http://www.hindawi.com
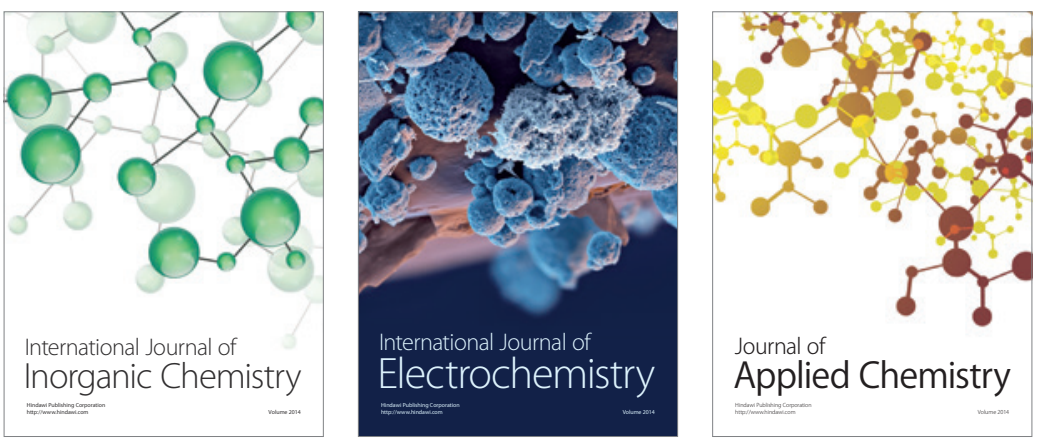

Journal of

Applied Chemistry
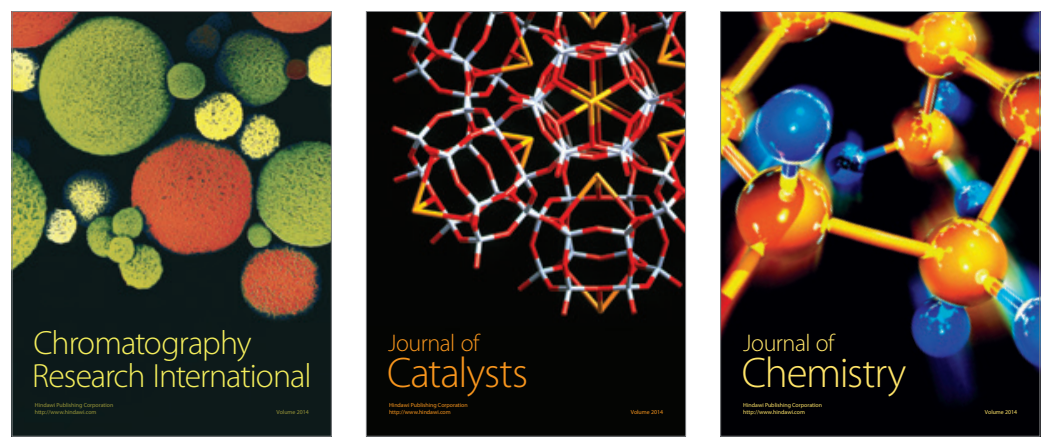
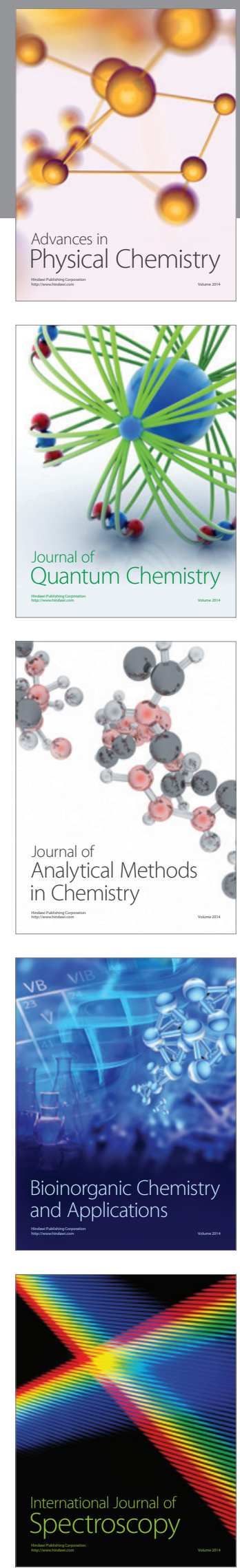